\title{
Ethical Perspectives in Work Disability Prevention and Return to Work: Toward a Common Vocabulary for Analyzing Stakeholders' Actions and Interactions
}

\author{
Christian Ståhl, Ellen MacEachen and Katherine Lippel
}

\section{Linköping University Post Print}

\section{Tweet}

N.B.: When citing this work, cite the original article.

The original publication is available at www.springerlink.com:

Christian Ståhl, Ellen MacEachen and Katherine Lippel, Ethical Perspectives in Work Disability Prevention and Return to Work: Toward a Common Vocabulary for Analyzing Stakeholders' Actions and Interactions, 2014, Journal of Business Ethics, (120), 2, 237-250. http://dx.doi.org/10.1007/s10551-013-1661-y

Copyright: Springer Verlag (Germany)

http://www.springerlink.com/?MUD=MP

Postprint available at: Linköping University Electronic Press

http://urn.kb.se/resolve?urn=urn:nbn:se:liu:diva-105559 


\title{
Ethical perspectives in work disability prevention and return to work: Toward a common vocabulary for analyzing stakeholders' actions and interactions
}

Running head:

Ethical perspectives in work disability prevention and return to work

Keywords:

Business; ethics; medicine; public administration; social insurance; work disability

\author{
Abbreviations: \\ CSR: Corporate Social Responsibility \\ ISCT: Integrative Social Contract Theory \\ RTW: Return-to-work \\ WDP: Work disability prevention
}




\section{Abstract}

Many studies have emphasized the importance of medical, insurance and workplace systems treating individuals fairly in work disability prevention (WDP) and return-to-work (RTW). However, ethical theories and perspectives from these different systems are rarely discussed in relation to each other, even though in practice these systems constantly interact. This paper explores ethical theories and perspectives that may apply to the WDP-RTW field, and discusses these in relation to perspectives attributed to dominant stakeholders in this field, and to potential differences in different jurisdictional contexts. Literature was sought primarily in biomedical ethics, business ethics, and public administration ethics. In biomedical ethics, four ethical principles are dominant: autonomy, beneficence, nonmalevolence and justice. Business ethics involve theories on Corporate Social Responsibility (CSR), social contracts and organizational justice. Public administration ethics focus on constitutional theory, citizenship, social equity, virtue and public interest. Several concepts were identified as relevant for ethical analyses in the WDP-RTW field, including justice; individual autonomy; nonmalevolence; economic and social responsibility; and social contracts. These concepts provide a vocabulary that may be used to analyze stakeholders' actions and interactions in RTW processes. It was also noted how the power balance between stakeholders will influence which ethical perspectives will influence RTW. Jurisdictional differences that influence RTW processes with regard to stakeholder responsibilities were identified, as well as varying beliefs as to who is the client in different compensation systems. A social contractual approach may inform an analysis of cultural and legal differences. 


\section{Introduction}

Over the last decade, the research fields of work disability prevention (WDP) and return to work (RTW) have expanded rapidly, and an increasing number of studies are placing emphasis on integrative approaches between disciplines and topics of study (Franche et al. 2005a; Loisel et al. 2005; Young et al. 2005; Bültmann et al. 2009; Loisel 2009; MacEachen et al. 2010). A systems perspective on issues relating to rehabilitation and RTW has become increasingly common: the interactions between personal, medical, workplace and insurance systems are recurrently discussed as influential for processes and outcomes of RTW (Loisel et al. 2005). Attention has also been directed to the influence of cross-country differences, indicating that different legislations and institutional structures have an impact on RTW (Anema et al. 2009).

In a review article, Franche et al (2005b) noted how RTW studies generally do not inquire about the effects of interventions on quality of life, and observed that the risks of premature RTW have been scarcely recognized. In several RTW studies, various problems in RTW processes have been targeted, which may prevent people from successfully regaining health and limit their abilities to provide for themselves through work (cf. Strunin and Boden 2000; Baril et al. 2003; Tjulin et al. 2010). Although there are implicit ethical implications of such problems (for instance, the balance between forcing early RTW, the sustainability of the worker's health, preventing stigma, and preserving dignity) these are generally not explicitly targeted as ethical issues in the analyses. It is rare to see an explicit focus on ethics in WDP or RTW. 


\section{Why an ethics approach?}

Ethics involves theories about which actions can be considered good, and the criteria that these actions should fulfill in order to be identified as such. Such theories have been presented since the ancient Greeks, and have historically represented different philosophical traditions, where the most common within normative ethics are deontological ethics (where actions are judged in relation to duties or rules, e.g. Kant's categorical imperative), consequentialism (where actions are judged in relation to their consequences, e.g. Bentham's utilitarianism), and virtue ethics (based on moral character, e.g. Socrates or Aristotle). In several scientific disciplines, ethical theories have been developed that are more specifically applicable to certain topics, for instance medicine, business or politics. Most applied ethical theories are based on or relate to normative theories, for instance by incorporating concepts based on deontological or consequentialist principles.

In the WDP-RTW field, professionals meet workers (and/or the unemployed, in compensation systems not based on work) on a daily basis and their actions have a direct impact on the individual's life. There are several examples of studies that demonstrate how individuals' selfperception, motivation and possibilities for returning to work can be influenced by the treatment from professionals in different systems. Studies of the workers' compensation system in Quebec showed how the system, by having processes that lead to questioning of the legitimacy of workers' claims, had anti-therapeutic effects (Lippel 1999; Lippel 2007). A number of studies have pointed to socio-economic, ethnic or gender differences in how individuals are treated in insurance systems (Lippel 2003; Gravel et al. 2010; Leinonen et al. 2011), as well as claimants' perceptions of diminished social justice in their interactions with compensation systems (RobertsYates 2003; Strunin and Boden 2004; MacEachen et al. 2007; Franche et al. 2009). It has been 
proposed that sick-listed individuals' perceptions of encounters with professionals determine whether the rehabilitation process will be experienced as empowering or disempowering (Müssener et al. 2008), and that professionals should focus on health, motivation and pride in their interactions with sick-listed individuals (Svensson and Björklund 2010). Other studies have pointed out how social insurance officials experience ethical dilemmas when balancing insurance regulations and claimants’ needs (Stensöta 2010; Ståhl et al. 2012). Finally, studies have found that workers who perceived fair treatment and recognition of their injuries from their employers in RTW processes reported fewer depressive symptoms than those who did not (Hepburn et al. 2010a). These studies all emphasize the importance of systems having procedures that enable fair treatment of individuals, which implies acknowledging the ethical dimensions of rehabilitation professionals' meetings with and treatment of people.

In the WDP field, three systems of professionals are commonly identified as present in RTW processes within most jurisdictions: workplaces, the health care system, and the insurance system (Loisel et al. 2005). Apart from these, workers' interests have also been targeted as a separate domain. Workers' interests have been discussed as relating to financial stability and happiness; employers' as productivity; health care providers as client health and not causing harm; payers' and society (in many countries represented by publicly funded and organized institutions) as profitability, sustainability and political harmony (Young et al. 2005). Other studies have identified stakeholder interests in similar ways, where employers are commonly associated with productivity, health care with individual health, insurance agencies with reducing sickness benefit payments, while individuals have been associated with quality of life and balance between work and family (Lindqvist 2003; Franche et al. 2005a). Although other stakeholders may be involved in WDP issues (e.g. unions; occupational health and safety inspectors; workers' families and 
social networks; policy makers; or the general public), these four (workplaces, health care system, insurance system, and workers) are commonly considered as central in RTW processes. This paper focuses on the three professional systems medicine, business, and insurance.

The different value systems among professionals may imply differences between which ethical perspectives that are commonly taken by stakeholders when assessing the usefulness of interventions. It is possible to discuss these perspectives as representing different "communities" governed by different priorities and values, all with their own discourse (cf. Luhmann's (1995) theories of social systems). Disconnections between each of these systems (for instance, through differing perspectives and communication failures) may add up, and risk forming a "toxic dose" of system-related problems that in the end may prevent individuals from returning to work (MacEachen et al. 2010).

Research on ethics has been more explicitly developed in research fields that may be considered as related to these different systems: medicine, business and social insurance. However, ethical theories and perspectives from these different systems are rarely discussed in relation to each other, even though in practice these systems constantly interact, as is evident in WDP research.

Bearing in mind these system-related differences, we believe it is necessary to attend to ethics as a relevant issue in the WDP-RTW field. Ethical issues are always present and they need to be considered in a more systematic way than has been done thus far. Further, it is relevant to study the ways that priorities of different stakeholders may influence RTW processes, and whose ethical perspective that in the end will determine the outcomes of such processes. It is therefore necessary to place ethics on the RTW agenda, and provide a vocabulary by which these issues may be discussed. 
The aim of this paper is to explore different ethical theories and perspectives in the WDP-RTW field, to discuss these in relation to the perspectives that in the literature are commonly attributed to the dominant stakeholders in this field, and to the potential differences related to different jurisdictional contexts. In doing so, the paper will offer brief descriptions of ethical theories within business, medicine and public administration, in order to introduce and discuss central concepts in the fields in relation to WDP and RTW.

\section{Methods}

This is a theoretically driven paper, where the purpose is to present theories and perspectives from different research traditions. The literature was sought through a non-systematic review, where focus was on overviews, handbooks and reviews of research conducted in three fields: biomedical ethics, business ethics, and public administration ethics. The goal was to identify, compare and contrast central issues and concepts, rather than to present an exhaustive or systematic review of the research fields in question.

The literature was collected through library searches in order to identify central handbooks covering the three fields. Here, the inclusion criteria were that the books provided an overview of the field in question, and that it presented different perspectives from the literature in this field, which was assessed through studying tables of contents and reference lists. Searches were also carried out in scientific databases (primarily Scopus and PubMed), to find review articles of the three fields. Journals identified as central were further searched for relevant articles in online archives. Papers that discussed ethical issues on a theoretical or conceptual level were sought; however, other papers were also included if they provided insights into the ways theories or 
concepts have been applied in research, or when they commented on central theories. For the review of ethical issues in a WDP-RTW context, database searches were carried out, where examples of keywords used were: ethics, justice, fairness, work disability, return to work, rehabilitation, public administration, health care, business, workplace, organizational, social insurance, sickness insurance, and workers' compensation. Different combinations of these words were tested. Reference lists of found studies in the WDP-RTW field were scrutinized for further references. Included overviews of the different fields were published in the last 15 years.

For biomedical ethics, the following sources were used for achieving an overview: Beauchamp and Childress (2009), Khushf (2004), Westerholm et al (2004), and Harris (2011), plus articles commenting on the ethical principles presented in these overviews. For business ethics, Rendtorff (2009), Dwyer (2008) and Reilly et al (2012) were used for an overview, while others were used for further information on certain traditions (e.g. Donaldson and Dunfee 1999; Schwartz and Carroll 2003). For public administration ethics, the following sources provided an overview: Cooper (2004), Martinez (2009) and Brady (2003).

The literature review of the three fields resulted in the identification of a set of ethical concepts, which in the analysis phase were cross-examined across the three fields, in order to identify similarities and differences between them. Since the study is theoretical and not empirical, the process of analysis was primarily an intellectual endeavour, and was done through continuous discussions between the authors. In the discussion, the theories were related to the different perspectives attributed to health care representatives, employers and insurance representatives in the WDP-RTW literature, and to potential jurisdictional and/or cultural differences. In this discussion, we found the three authors' different backgrounds and experiences useful (a Swedish sociologist, a Canadian social scientist from Ontario, and a Canadian legal scholar from Quebec). 


\section{Results}

In this section, central concepts, theories and perspectives from biomedical, business, and public administration ethics are presented separately. In the discussion, these perspectives are compared and discussed in relation to their applicability in the WDP-RTW field, and to different jurisdictional contexts.

\section{Biomedical ethics}

Conceptualizations of bioethics involve differing between consequentialist (e.g. utilitarianism) and non-consequentialist (e.g. deontological theories) ethics (Harris 2011). Khushf notes that bioethics comprises several theories, although "grown up from the same soil, with similar kinds

of experiences" (Khushf 2004, p. 7), which implies that the different theories have many common features. The bioethical field can also be said to have certain specialties, such as clinical ethics (moral dilemmas in care of patients), ethics of health policy (such as implementation of advances in science) and philosophical bioethics (Khushf 2004). In health care practice, promoting evidence-based care can be framed from an ethical perspective, although the ethics of evidencebased practice have been questioned (cf. Goodman 2002).

\section{Principlism}

According to Beauchamp and Childress (2009), consequentialist and deontological theories can be characterized as monistic, by giving priority to certain ethical principles over others. Ethics in the health care system is commonly rooted in a number of basic principles, where multiple principles may apply simultaneously in a given situation. A system of such principles proposed 
by Beauchamp and Childress (2009) has become highly influential. Often referred to as principlism, it makes a distinction between four principles: autonomy, beneficence, nonmalevolence and justice. The principles of nonmalevolence and beneficence have a long tradition in medical ethics, while the principles of autonomy and justice were introduced more recently. The simultaneous recognition of several principles makes principlism a pluralistic stance.

- Autonomy concerns individuals' right to decide about their health and personal life. For health care professionals, respect for autonomy involves making sure that patients provide informed consent to treatment. This principle may prove to be complicated in cases where the patients are not able to make decisions about themselves, due to functional or mental disabilities.

- Nonmalevolence (to avoid doing harm) is by long tradition a central governing concept in the health care professions. Although it may seem obvious that treatment is meant to improve patients' health conditions, some treatment may involve risks. Further, this principle concerns whether life-sustaining treatments and aid-in-dying should be acceptable.

- Beneficence adds to the principle of nonmalevolence and suggests that health care professionals should actively promote the well-being of others. This, for instance, involves a duty to act if somebody is in need and the professional has the possibility of helping. The beneficence principle may conflict with the principle of autonomy if patients refuse treatments that the professionals consider necessary for their survival. In such a case, the professional may risk acting in a paternal manner. The attention to medical paternalism has increased as an effect of the more common assertions of autonomy rights. 
- Justice as a principle for biomedical ethics concerns the distribution of resources in relation to peoples' needs. Beauchamp and Childress have identified four theoretical perspectives for determining distributive justice: utilitarian (maximizing value),

libertarian (market-based), communitarian (rights-based) and egalitarian (social equity). This principle may thus be interpreted quite differently, and relates to discrimination, vulnerability, and, ultimately, the design of health care systems. Within each system, professionals will need to prioritize people's needs, and the design of the system will have an influence on which patients will receive treatment. Beauchamp and Childress have "primarily sided with egalitarian and utilitarian theories" (2009, p. 280), and support the idea of everybody's right to a minimum of health care through policies of just access to health care, efficiency in health care institutions and global needs for reduction of healthimpairing conditions.

Within biomedical ethics, none of the four principles is seen as having priority over another: rather, every action should be sensitive to the balance between them. Situations may occur where one or more of the principles must be infringed upon in order to uphold another, in which case the health care professional should be able to explain how the specific action prevents a less preferable alternative. Ethical dilemmas arise when different principles apply to the same situation, and where it is necessary for the professional to make a choice (Beauchamp and Childress 2009).

\section{Criticisms of and additions to principlism}

Although influential and widely accepted, Beauchamp and Childress' system has received criticism. For instance, Herrisone-Kelly (2011) has questioned whether the four principles are globally applicable other than on a strictly conceptual basis, as health care systems differ between 
countries. Another critique refers to Beauchamp and Childress' suggestion that no one principle should have priority over the others, and that the system of principles offers little guidance for professionals having to choose between them (Lawrence 2007).

In occupational health care, the conditions differ slightly from other health care settings due to the tight connection to workplaces, making occupational health ethics oriented towards individuals as well as workplaces (Westerholm et al. 2004). While acknowledging the principles identified by Beauchamp and Childress, Westerholm adds working conditions, stakeholder influences and multiple loyalties as important factors when making ethical choices (Westerholm 2007). Ethical problems are considered to be practical issues, which implies that the professional will need to consider the consequences for different stakeholders when making ethical choices (cf. consequentialist approaches to ethics). The occupational health professional will need to consider not only the interest of the worker, but also the employer's and the occupational health service's interests. These choices require that the professional is able to identify conflicting principles and make choices among them, based on how the professional values these principles (Westerholm 2007). Similarly, private sector rehabilitation practitioners need to balance patients' needs for services with their organizations' need to control costs; ethical dilemmas often involve conflicts between individual autonomy and beneficence, and between fidelity to organizational processes and beneficence (Vaughn 1998).

\section{Business ethics}

Research on business ethics may involve different theoretical approaches, which have been classified by Rendtorff into three categories: 1) organization studies and institutional theory; 2) 
corporate social and political theory; and 3) business ethics and stakeholder analysis (Rendtorff 2009). Studies of ethics in a workplace context may, in turn, be labeled workplace ethics, or quality of work life (Rendtorff 2009; Reilly et al. 2012).

In research on corporations' value systems and actions, a distinction can be made between stockholder theories which focus solely on maximizing profits for business owners, and stakeholder theories which allow for focus on broader interests (Dwyer 2008). In a stakeholder view, the beneficiary of business may be broader than the business owner, since other stakeholders also may have interests in the business (e.g. employees, local communities, or customers). Here, an ethical perspective is more relevant due to the broader types of responsibilities attributed to corporations.

\section{Corporate Social Responsibility}

One of the most common and influential concepts in the business ethics literature is Corporate Social Responsibility (CSR). CSR refers to a vast array of theories dating back to the 1950s, when the concept initially dealt with the social responsibilities of corporations. Later theories have added a focus on stakeholder management, corporate accountability, public policies and more (Garriga and Melé 2004). Maignan and Ferrell (2004) summarize CSR conceptualizations into four categories: CSR as social obligation, as stakeholder obligation, as ethics driven, and as managerial processes. None of these conceptualizations has been entirely dominant; the research field has been characterized by its diversity, varying from managerial or instrumental approaches (determining, for instance, how CSR can generate organizational benefits) to normative standpoints (Maignan and Ferrell 2004). 
Carroll (1991) offers one of the most cited descriptions of the CSR concept (pertaining to CSR as social obligation, as defined by Maignan and Ferrell 2004), in which it is conceptualized along four dimensions: economic, legal, ethical and philanthropic. These are commonly depicted in a pyramid model, with economics at the bottom and philanthropy at the top. Economic responsibilities refer to requirements of being profitable; legal responsibilities to obeying the law; ethical responsibilities to doing right and avoiding harm; and philanthropic responsibilities to contribute resources to the community (Carroll 1991). Economic and legal responsibilities are generally required for any corporation. Shareholders, owners and the public may expect most corporations to fulfill certain ethical responsibilities, understood as performance "in a manner consistent with expectations of societal mores and ethical norms" (Carroll 1991, p. 41), while philanthropic responsibilities are more often a desired rather than a required feature. The pyramid model was later developed into a Venn diagram, in order to better capture the interrelatedness of the domains, and to avoid misinterpretations (where some scholars had interpreted it as giving priority to either the domain at the top, or the one at the bottom). In the later model, the philanthropic domain is integrated within the ethical, and the three domains overlap into forming different categories in which corporate actions may be placed: economic, legal, ethical, or combinations of any of the three (Schwartz and Carroll 2003). Each of the domains comprises different sorts of motivations for actions. Actions in the economic domain are aimed at maximizing profits and share value. Actions that fall into the legal domain may be carried out in passive compliance with the law (i.e. non-reflected), restrictive compliance (actions that would not have been carried out without the law), opportunistic compliance (e.g. making use of loopholes in order to engage in certain activities), in avoidance of civil litigation, or in anticipation of the law (e.g. changing practice before a new law is introduced). According to Schwartz and Carroll, actions in the ethical domain may refer to conventional, consequential or 
deontological ethical standards, where conventional standards refer to formal codes of conduct, consequentialism to promoting higher ends than company profits, and deontology to moral duties and justice (Schwartz and Carroll 2003).

Although economic responsibilities (especially being profitable) are generally highly valued in corporations, most actions will reflect overlaps between the domains. For instance, economic actions are most often also carried out in a manner which complies with the law, in some of the meanings noted above (where an example of complying with legislation although in an ethically questionable manner could be to use a globalized market to choose business friendly jurisdictions for production, Murray 2010). Actions in the ethical domain are generally in compliance with the law (while illegal activities are often unethical), and ethical actions are often considered profitable in a longer term perspective, as illustrated by the maxim "good ethics is good business" (Schwartz and Carroll 2003).

While many CSR theories aim to describe how corporations relate to broad social norms and societal obligations, there are also more narrow definitions of the concept, focusing more on responsibilities toward stakeholders than to society as a whole. Stakeholders, in turn, may be categorized into organizational (e.g. employees, customers, shareholders), community (e.g. local residents), regulatory bodies and media stakeholders (Maignan and Ferrell 2004). As Balmer et al (2007) point out, this more tailored view on CSR still involves quite extensive obligations for corporations.

There are also a range of theories on corporate identity, citizenship and accountability, aiming to theorize the responsibilities and public images of a corporation, and explaining how this is related to internal affairs within the corporation. Corporate identity can be further divided into actual, 
communicated, desired, ideal and conceived identity, which elaborate the variety of ways a corporation is perceived internally and externally (Balmer et al. 2007). A corporate ethical identity is seen to be formed relationally between parties, where the management of such identities requires a socially and dialogically embedded corporate practice (Balmer et al. 2007). It has however been noted that stakeholder dialogue may be considered as a defensive practice aiming to prevent stakeholders from taking action against the corporation (e.g. through governmental interventions); in such situations, CSR is applied in order to neutralize corporate behavior, for instance by defending legality, denying responsibility, or expressing rights (Fooks et al. 2013).

While CSR theories often have been used to analyze environmental responsibilities and the public image of corporations, they have also been criticized for neglecting workplace equality and safety issues (Hart 2010). Some CSR studies have focused more extensively on power relations among stakeholders in the workplace, and on issues related to the globalization of work (Murray 2010). Literature on workplace ethics is generally more applied to working conditions and relationships between employers and employees, and may involve a number of different topics, e.g. job quality, gender equality, discrimination, health and safety, work organization and skills development (Bateman 2012). Here, the focus is primarily on ethics on an organizational level, acknowledging the mutual commitment between employer and employee that is a part of an employment contract. This implies that the status of business ethics "lies somewhere between concerns for economic efficiency on the one hand, and respect for basic ethical principles of human autonomy, dignity, integrity, and vulnerability on the other" (Rendtorff 2009, p. 222-223). Analyses of organizational codes of ethics have concluded that the scope of such codes has increased over recent decades, and that these nowadays generally include respect for individuals' 
rights and dignity, beneficence/nonmalevolence, responsibility, integrity and justice (Bateman 2012). However, as noted by Weaver et al (1999), the implementation of ethics policies can be superficial or symbolic, and may not be supported by ethics-specific structures, personnel or activities.

\section{Integrative Social Contracts Theory}

Another perspective on business ethics is the social contracts approach. Donaldson and Dunfee (1999) introduce their Integrative Social Contracts Theory (ISCT) by discussing two problems: the problem that business ethics has been divided in empirical and normative traditions, with their respective methodologies; and problems with cultural diversity, i.e. that ethics may be perceived differently in different contexts. They critically consider the Rawlsian idea of a "view from nowhere", which they interpret as a philosophical idea with a clever purpose - that is, to remove all positional bias when settling upon principles for justice and fairness. Business, the authors argue, is however 'inescapably 'artifactual', or, in other words, inescapably dependent upon convention and agreement for its shape and character" (Donaldson and Dunfee 1999, p. 14). The world of business is "institutionally thick", while ethical theories (especially normative theories) are generally institutionally thin, and do not apply similarly across contexts. Social contract reasoning, on the other hand, is better suited to analyze business ethics issues because it reflects the "thickness" of business practices and institutions. Still, Donaldson and Dunfee argue that social contracts (i.e. local norms) need to be consistent with broader, internationally accepted ethical principles (hypernorms) in order to be considered as obligatory or legitimate. It is, for instance, possible to have local norms that are immoral when viewed in relation to broader ethical theories (Donaldson and Dunfee 1999). Through this approach, ISCT highlights pluralism, not relativism; tolerance but not amoralism. The social contracts on a micro level fill in what the 
macro-ethical theories leave out, thus facilitating the adaptation of broad principles to local contexts.

Also within corporations, studies have focused on how managerial responsibilities are dependent on social contracts, as socially constructed and based on negotiated orders (Baïada-Hirèche et al. 2011), and how treatment of disabled employees are influenced by a combination of individual morals, social norms and legislated obligations (Barclay and Markel 2009). This may be seen as an approach related to ISCT, where the perspective on corporate (and managerial) responsibility is believed to be context specific and intertwined with social and cultural norms, be they organizational or societal.

\section{Organizational justice}

In research on organizational justice, two often cited studies have offered meta-analyses of how different types of justice may be conceptualized (Cohen-Charash and Spector 2001; Colquitt et al. 2001). Cohen-Charash and Spector (2001) distinguish three forms of justice: distributional, procedural and interactional. Distributional justice refers to the outcomes an individual receives in terms of salary or benefits; procedural justice is concerned with the process leading up to these outcomes and more generally to the way individuals are treated; and interactional justice refers to the personal relationship between the individual and the person representing the organization. Colquitt et al (2001) have divided interactional justice into two categories: informational and interpersonal justice. Both meta-analyses conclude that the different types of justice are distinguishable, yet highly correlated, and that work performance and organizational behavior is

generally influenced by all three (or four) types (Cohen-Charash and Spector 2001; Colquitt et al. 2001). 
Research on organizational justice can be placed in a broader theoretical context of ethical behavior in organizations, although the former often has ignored the normative aspects of ethical theory (Treviño et al. 2006). Research on behavioral ethics is primarily concerned with the relationships between individual characteristics and organizational contexts, although the connection to global business ethics have often been neglected (Treviño et al. 2006).

Understandings of organizational justice are in some respects similar to the biomedical principles identified by Beauchamp and Childress, in particular the references to fair distribution of health care resources, and respect for patients' autonomy (Beauchamp and Childress 2009). It is however likely that the perspective on distributive justice would differ depending on the design of the health care system, where a market-based system would be less concerned with social equity than a tax-funded egalitarian system (cf. the integration of contextual and general ethical norms, Donaldson and Dunfee 1999).

\section{Public administration ethics}

In the field of ethics in public administration, Cooper (2004) has identified five normative traditions that all have an impact on decision-making in public organizations: constitutional theory, theories on citizenship, social equity, virtue, and public interest.

- Constitutional theory refers to regime values and the idea that officials in government jobs need to be aware of the values of the organization and their obligation to uphold them.

- Citizen theory focuses officials as representatives of the public, or society, where respect for individual dignity and concern for the common good is emphasized. 
- Social equity is largely based on the writings of John Rawls, who argued that justice is the central organizing principle of government (Rawls 1971). This refers primarily to fair distribution of common goods, where governmental service delivery should be organized in a way that does not disadvantage those with few resources. This reasoning is based upon the thought experiment labeled the "original position", where rational individuals are believed to prefer egalitarian principles if they would be placed under a "veil of ignorance", i.e. not being aware of their position in society (Rawls 1971). Rawls approach, Donaldson and Dunfee argue, needs to be complemented with contextual and cultural sensitivity when applied to specific situations, by incorporating the idea of social contracts that integrates local norms and broad ethical principles (Donaldson and Dunfee 1999).

- Virtue refers to the cultivation of a democratic ethos in public organizations.

- Public interest, finally, is identified as probably the "most widely recognized and most generally espoused normative touchstone for public administration ethics" (Cooper 2004, p. 398), referring to whether actions taken by officials are carried out on behalf of broad shared interests or limited particular ones.

The concept of "public interest" may be interpreted in different ways. Vonk \& Tollenaar (2010) asked scholars from different disciplines whether they would consider social security to be of public interest, which they concluded it to be after considering contributions from economics, public administration, philosophy and law, albeit supported by different arguments. Economists argue that public interest refers to the maximizing of the benefits of economic transactions for society; public administration identifies public interest with upholding of values; law defines public interest through fundamental socio-economic rights (of which social security is one, 
according to the authors) and obligations; and philosophy identifies it as an expression of justice (Vonk and Tollenaar 2010). These understandings of the public interest are, however, influenced by the authors' political and cultural heritage (all authors in the volume being Dutch), and it is possible that scholars from other contexts would interpret the concept of public interest differently, notably with regard to social security. Generally, the perspective of public interest has been influential in public administration ethics across political contexts, although the understanding of it may differ.

Several authors have pointed out that different theoretical perspectives co-exist in the field (Brady 2003; Cooper 2004; Martinez 2009). A widely recognized and accepted theoretical framework for public administrations has not been considered feasible, as public officials will in their practice face situations where different ethical perspectives would result in different decisions that would all be ethically defensible (Martinez 2009). In some cases, an official may need to sidestep administrative regulations to meet an individual's needs, in which case the official can be torn between the loyalties toward his or her superiors (which are generally strong in public organizations), the law, and the citizen (Lundquist 2007). Although different decisions in such a situation may be ethically defensible, they would be so on different grounds. Examples like these illustrate how ethical dilemmas in public administration are practical (cf. the discussion about ethical choices in health care above), and arise when different norms lead to conflicting solutions to be applied to the same situation (Westerholm 2007). Compared to biomedical ethics, where professionals also face dilemmas that several choices could defend, public administration ethics lack a widely recognized set of principles that may guide the professionals in making decisions. 
In a study of Norwegian public officials’ ethical perspectives, Christensen \& Laegrid (2011) identified both deontological and consequential ethical approaches, and they concluded that the application of ethical frameworks in organizations is always context specific. This, one may assume, is equally true regarding different organizational, political and cultural contexts (cf. Donaldson and Dunfee 1999). Ethical dilemmas in public administration practice should not, according to Brady (2003), be treated as administrative problems: rather, they should be considered as a "reality check" for the organization, where human differences must be managed within a standardized social insurance system. Cooper (2004) also noted how a standardized system cannot guarantee a fair process for everybody. Many will feel unfairly treated by large bureaucracies, for instance in simplistic policies aiming to promote re-entry onto the labor market that take little heed of individual needs (MacEachen et al. 2012). Cooper has argued for a combination of standardization and variety, which is also reflected in Stensöta's observation that client orientation (i.e. toward sick or injured individuals) and rule orientation among officials should be seen as complementary rather than as opposites, where officials in their contacts with clients combine and balance the ethics of care and the ethics of justice as two ethical dimensions in public welfare administration (Stensöta 2010). Again, different cultural or political contexts may lead to different orientations, and the "client" may vary from one jurisdiction to the next. For instance, in some North American workers' compensation systems, employers rather than workers may be perceived as clients (Eakin et al. 2009), while this would not be the case in Scandinavian systems. 


\section{Summary}

In Table 1, concepts identified as central to the three fields have been divided into their potential application on different levels: an individual (concerning interactions with patients, employees or claimants), an organizational (concerning professional ethics, or other organizational aspects), and a societal (concerning the relation to society as a whole). The table may serve as an analytic grid to identify relationships between concepts from different fields.

(Table 1 about here)

\section{Discussion}

In the WDP-RTW field, there are several potential ethical perspectives, stemming from different research and cultural traditions. In this section, the central concepts in the three research fields outlined above will be discussed in terms of similarities, differences, potential differences across jurisdictional contexts, and their applicability to the WDP-RTW field.

\section{Theoretical similarities and differences}

On a theoretical level, some ethical principles appear common to all three fields, such as fair treatment of people, avoiding harm and respecting the law (similar to what Donaldson and Dunfee (1999) label "hypernorms"), although conceptualized differently in different ethical traditions. For instance, beneficence in bioethics is comparable to the ethical or philanthropic 
domain of CSR in business ethics. The understanding of autonomy in medicine is closely related to the understanding of citizenship in public administration, where respect for the individual's dignity is central, which has also been mentioned in relation to organizational codes of ethics in corporations. In medicine and public administration, justice is closely linked to social equity and the public interest, while in business it is more of an intra-organizational concept, pertaining to the relationship between the corporation and its employees. Constitutional values, as discussed in public administration ethics, may be translated into corporate codes of ethics, or to allegiance to the tradition and values of nonmalevolence in health care. Economic responsibility is a primary concern for businesses, although public administrators through their responsibility for benefit systems must also take such issues into account. In workers' compensation systems (for instance, systems in the US or Australia), compensation providers may be private actors with a more direct focus on profit, which would make economic responsibility a prime priority (and may potentially risk overriding other factors when making decisions). Economic responsibility may also be relevant for health care providers, since the needs of individuals will be balanced in relation to available resources. The extent of this aspect will reasonably vary between different health care systems.

In many cases, it would thus appear that different research fields have been preoccupied by similar questions, but analyze them through their respective traditions, which has led to the use of separate vocabularies and sometimes to different conclusions.

Although the different conceptual frameworks of biomedical ethics, business ethics, and public administration ethics may not be fully interchangeable, there are examples of concepts from the different fields having been combined. In studies of claimants' perceptions of justice from workers' compensation boards, researchers have successfully employed concepts from business 
ethics (organizational justice) and found them applicable to a field more related to public administration (Roberts and Young 1997; Franche et al. 2009). Franche et al. concluded that organizational justice forms (distributive, procedural, informational and interpersonal) were applicable to the relationship between claimants and insurance representatives, and that the workers' claim status, time to RTW and level of work accommodations may be related to how the workers perceived the fairness of their treatment (Franche et al. 2009). This use of the concepts was thus carried out on the individual level, where interactions between insurance officials and claimants were targeted. Concepts of organizational justice have also been used to analyze the relationship between employers' response to injuries and workers' attitudes and mental health (Hepburn et al. 2010a; Hepburn et al. 2010b). Studies of health care in private sectors (including occupational health care) have incorporated concepts and arguments from medical as well as business ethics (Vaughn 1998; Westerholm 2007).

Further, the attention to stakeholder interests in RTW research has similarities with the way business ethicists conceptualize the responsibilities of a corporation in relation to the stakeholders involved. Stakeholder theories in business ethics are however generally broader, identifying interests more inclusively (for instance, including public opinion, customers, suppliers, etc.) while RTW research is often limited to those interests of workers and unions, employers, health care systems and insurers. RTW researchers often combine attention to stakeholders with a systems approach (c.f. Loisel et al. 2005) which has similarities to social contracts theories in business ethics (Donaldson and Dunfee 1999; Baïada-Hirèche et al. 2011), in explaining how stakeholder interests relate to each other. A social contracts approach may also facilitate analysis of how different local interests are integrated with broader cultural norms and ethical principles. 
Attention to different ethical vocabularies could inform empirical analyses of situations where representatives from different systems may be in conflict, as well as identifying common grounds. Although many of the concepts overlap in theory, the dominant logics underpinning different systems imply that professionals aligned with health care centers, corporations and insurance institutions cannot be expected to react or act similarly in similar situations (cf. Franche et al. 2005a; Young et al. 2005). Schwartz and Carroll (2003) discuss how there may be different CSR "portraits" (economic, legal, ethical or balanced orientation), and in the same fashion, the different perspectives on ethics could be differently weighted. Further, stakeholder groups are not homogeneous, which implies that it is not obvious how a certain stakeholder will act; for instance, differences in employers' attitudes toward returning workers have been noted "welcome back", "business as usual" or "you're out" (Strunin and Boden 2000) - where these attitudes reflect different stances toward ethics in RTW, although they all represent employers. Similarly, economic limitations within health care may make certain treatments impossible in one health care system, but not in another.

\section{Targeting cultural and political differences}

Beauchamp and Childress' principles for biomedical ethics have been criticized for not being applicable across cultures and political contexts (Herrisone-Kelly 2011). It is likewise reasonable to assume that the ethical aspects of the CSR concept vary both across and within different countries, where a social contracts approach may serve as a remedy to such issues. Hart (2010) has further criticized the way that CSR is often applied as an overarching evaluation of a company's ethical record. This bundling of components makes it difficult to identify inconsistencies in their actions. Hart (2010) argues that CSR in practice most often focuses on 
environmental responsibility, and fails to acknowledge social or labor issues; thus giving more attention to the public image of a corporation in relation to the other aspects that make up a company's corporate identity (cf. Balmer et al. 2007). In this sense, the jurisdictional context is also of importance, since the responsibilities of corporations differ greatly with regard to labor legislation across countries (Donaldson and Dunfee 1999; Murray 2010); employers' financial responsibilities for participating in RTW processes, for instance, differ greatly across jurisdictions.

While corporations may be international organizations with similar cultural underpinnings, the ethical perspectives around the world may still be quite different, as noted by Dwyer: "companies doing business in China have encountered deeply rooted business traditions that, from the perspective of Chinese employees, are entirely ethical, even paradigmatically ethical and obligatory, yet these traditions fly in the face of Western conceptions of business ethics" (Dwyer 2008, p. 13). Further, other stakeholders are not at all international: health care and insurance systems are clearly rooted in their geographical and political contexts, which affect the ethical frameworks that prevail in the different systems. For instance, workers' compensation is the responsibility of the state in all provinces in Canada; in the US, the legal framework governing workers' compensation is the responsibility of the state, while the implementation of the program is, in most states, the responsibility of private insurance companies. It is possible that the actors responsible for implementing such programs may be driven by principles more closely associated with business than with public administration ethics.

Differences in illness and injury compensation systems not only determine different conditions for decision-making by insurance officials: such differences will affect all other stakeholders' actions as well. For instance, the ways different compensation systems provide economic 
incentives to promote RTW differ. In some systems, this incentive is primarily put on the employer, as in the Netherlands, where the employer has a two year financial responsibility for the worker; other systems provide economic incentives only for the worker, such as in Sweden, where sick-listed workers risk losing their benefits while employers generally lack economic incentives for engaging in RTW (de Boer et al. 2004). Different systems thus create different ethical issues, implying that the stakeholders' loyalties, priorities and perspectives will differ substantially. Stakeholders' behaviour will differ, and similar behaviour will be likely to have different ethical implications in different systems. Employer responsibilities will influence what decisions managers need to take in order to comply with regulations, which will in turn influence how workers are treated. Similarly, systems that provide substantive protection and that successfully reduce adversarial interactions have been identified as being better at promoting claimants' dignity (Lippel 2012).

Different compensation systems also have different perspectives regarding who is the "client". This could be perceived, by some, to be the employer, as in many workers' compensation systems, an attitude attributable to the fact that employers fund the system (MacEachen et al. 2007; Eakin et al. 2009); or the individual on sick-leave, as in tax-based sickness insurance systems, such as in Sweden (Lindqvist 2003; Stensöta 2010). However, seeing sick-listed people as unwanted costs is not entirely uncommon even to Nordic countries. Reference to economic responsibilities, as per business ethics, may further be put forward as a legitimate reason to introduce cuts in the system. For instance, debates exist about the need to lower sickness absence figures, and the need to make social insurance systems more "insurance-like" (Baker and Simon 2002), often implying adoption of principles from private insurance. It has also become increasingly common to introduce managerial systems adapted from industry (such as lean 
production) into health care and other public organizations (cf. Radnor et al. 2012), which could further illustrate how business ethics are adapted by sectors traditionally dominated by other discourses or practices.

\section{Application to the WDP-RTW field}

Several studies have identified problems or shortcomings in the different systems (workplaces, health care systems and compensation systems) involved in managing WDP and RTW (Lippel 1999; Strunin and Boden 2000; Lippel 2003; Strunin and Boden 2004; Franche et al. 2009; MacEachen et al. 2010), where many of the problems, such as claimants' experiences of unfair treatment, or problematic RTW procedures in workplaces, could be considered to have ethical implications. Although analyses seldom incorporate a clearly expressed ethical perspective, many of the concepts identified above could inform such an analysis. For instance, insurance institutions' or employers' discrimination against certain groups could be analyzed from either a legal or a social equity framework; or, employers' resistance to taking measures to improve occupational health or adjust workplaces could be analyzed from a CSR perspective, or by applying the concepts of organizational justice.

As different stakeholders have different approaches to RTW processes, the question may arise as to whose ethics should be given priority. An example from RTW practice is the assessment of a worker's ability to work, where different perspectives lead to different consequences, all with different ethical implications. In a recent Swedish study, this process was characterized as a negotiation between employers, health care professionals and insurance officials, in which employers were identified as holding the "trump card". That is, if the manager said a person 
could not work, this person would not be returning to that workplace (Seing et al. 2012). Here, it is possible to speak of a "bottom line ethics", where the priorities are set by the stakeholder that holds the power to influence the process.

Further, it is possible to consider ethics at different points in the RTW process. Here, employers' occupational health and safety procedures could be considered to have ethical implications, since they will influence the health of their workers and the risk of becoming injured or work disabled. Similarly, RTW policies have ethical implications in how the employer treats injured or sick workers, as this can influence the worker's self-esteem and health. An example could be if RTW was prevented by an employer's unwillingness to adjust the workplace, where the concept of employers' economic self-interest would have a high explanatory value. In an analysis, this could be contrasted with, for instance, consideration of whether employers respect the principles of nonmalevolence or individual autonomy, and to what extent the social responsibility of the company is being met, in relation to local and cultural norms. In such a situation, the potential conflict with insurance or health care institutions could be analyzed through these stakeholders' differing ethical perspectives, and whether the worker is perceived as a patient, a citizen, or an employee.

The definition of stakeholders' roles is thus relevant to how their responsibilities will be perceived. Different perspectives lead to different priorities that are based on the values of the respective stakeholders. Although employers, insurance administrators or health care professionals cannot be understood as homogenous groups, they do represent different systems in which actors have different perspectives and loyalties, as expressed in their respective vocabularies. These vocabularies and actions are, further, highly influenced by the characteristics 
of the insurance system in which they operate, where a social contractual approach may inform an analysis of cultural and legal differences.

\section{Study limitations and directions for further research}

The purpose of this paper was explorative and aimed to compare and contrast key theories rather than to provide an exhaustive review of the literature. As such, the presentation of theories is simplified, and this paper does not aim to or offer a full description of the complexity of each theory. Other relevant concepts and theories are not presented here, due to the need to focus on a selection of concepts assessed as central to the fields of study. The literature review was based on sources that presented the three theoretical fields in broad terms (handbooks, reviews etc.), which reduces the risk that central theories have been overlooked. This paper should thus be considered as an attempt to introduce a theoretical vocabulary on ethics into the WDP-RTW field as derived from different related research fields. Future studies may suggest developments and applications of the ideas presented here.

The authors represent two countries, three jurisdictions, and two disciplines, which may have influenced how the theories were selected, and how they were applied to the WDP-RTW field. Ideally, transdisciplinary research that incorporates a systems approach to WDP and RTW could determine how perceptions of ethical issues differ in practice, and thereby help to form empirically informed analyses on RTW ethics, for instance, between countries with different social insurance systems (cf. Esping-Andersen 1990; Korpi and Palme 1998). 


\section{Conclusions}

Many studies have emphasized the importance of medical, insurance and workplace systems treating individuals fairly in work disability prevention (WDP) and return-to-work (RTW). However, there are currently few examples of studies in which ethical theories and perspectives from these different systems are discussed in relation to each other, although there are several examples in which the systems interact in practice. This article has explored overviews of different ethical theories and perspectives with relevance to the WDP-RTW field, and discussed central concepts in relation to perspectives attributed to the dominant stakeholders in this field, and to differences across jurisdictional and cultural contexts.

Several concepts were identified as relevant for ethical analysis in the WDP-RTW field, such as justice; individual autonomy; nonmalevolence; economic and social responsibility; and social contracts. These concepts provide a vocabulary that may be used to analyze different stakeholders' actions and interactions in RTW processes, on an individual, an organizational or a societal level. It was also noted how the power balance among stakeholders will influence which ethical perspective will be applied in RTW. Professionals in health care as well as in insurance systems may encounter ethical dilemmas regarding which different choices (sometimes all ethically defensible) lead to different consequences. Several jurisdictional and cultural differences were also identified that may influence RTW processes: different compensation systems are based on different socio-political underpinnings (for instance, tax-funded or marketbased systems) and may differ with regard to stakeholder responsibilities, and varying beliefs as to who is the client in the system. A social contractual approach may inform an analysis of such cultural and legal differences. 


\section{References}

Anema, J. R., A. J. M. Schellart, J. D. Cassidy, P. Loisel, T. J. Veerman and A. J. van der Beek (2009). "Can Cross Country Differences in Return-to-Work After Chronic Occupational Back Pain be Explained? An Exploratory Analysis on Disability Policies in a Six Country Cohort Study." Journal of Occupational Rehabilitation 19(4): 419-426.

Baïada-Hirèche, L., J. Pasquero and J. F. Chanlat (2011). "Managerial Responsibility as Negotiated Order: A Social Construction Perspective." Journal of Business Ethics 101(SUPPL.1): 17-31.

Baker, T. and J. Simon (2002). Embracing Risk. Embracing Risk: The Changing Culture of Insurance and Responsibility. T. Baker and J. Simon. Chicago, The University of Chicago Press.

Balmer, J. M. T., K. Fukukawa and E. R. Gray (2007). "The Nature and Management of Ethical Corporate Identity: A Commentary on Corporate Identity, Corporate Social Responsibility and Ethics." Journal of Business Ethics 76(1): 7-15.

Barclay, L. A. and K. S. Markel (2009). "Ethical fairness and human rights: The treatment of employees with psychiatric disabilities." Journal of Business Ethics 85(3): 333-345.

Baril, R., J. Clarke, M. Friesen, S. Stock and D. Cole (2003). "Management of return-to-work programs for workers with musculoskeletal disorders: a qualitative study in three Canadian provinces." Social Science \& Medicine 57(11): 2101-2114.

Bateman, C. R. (2012). Professional Ethical Standards: The Journey Toward Effective Codes of Ethics. Work and Quality of Life: Ethical Practices in Organizations. N. P. Reilly, M. J. Sirgy and C. A. Gorman. Radford, Springer.

Beauchamp, T. L. and J. F. Childress (2009). Principles of biomedical ethics New York, Oxford University Press.

Brady, F. N. (2003). "'Publics" Administration and the Ethics of Particularity." Public Administration Review 63(5): 525-534. 
Bültmann, U., D. Sherson, J. Olsen, C. L. Hansen, T. Lund and J. Kilsgaard (2009). "Coordinated and tailored work rehabilitation: A randomized controlled trial with economic evaluation undertaken with workers on sick leave due to musculoskeletal disorders." Journal of Occupational Rehabilitation 19(1): 81-93.

Carroll, A. B. (1991). "The Pyramid of Corporate Social Responsibility: Toward the Moral Management of Organizational Stakeholders." Business Horizons(July/August): 39-48.

Christensen, T. and P. Laegrid (2011). "Ethics and Administrative Reforms." Public Management Review 13(3): 459-477.

Cohen-Charash, Y. and P. E. Spector (2001). "The role of justice in organizations: a meta analysis." Organizational Behavior and Human Decision Processes 86(2): 278-321.

Colquitt, J. A., D. E. Conlon, M. J. Wesson, C. O. L. H. Porter and K. Y. Ng (2001). "Justice at the Millennium: A Meta-Analytic Review of 25 Years of Organizational Justice Research." Journal of Applied Psychology 86(3): 425-445.

Cooper, T. (2004). "Big Questions in Administrative Ethics: A Need for Focused, Collaborative Effort." Public Administration Review 64(4): 395-407.

de Boer, W. E. L., V. Brenninkmeijer and W. Zuidam (2004). Long-term disability arrangements: A comparative study of assessments and quality control, TNO Work and Employment.

Donaldson, T. and T. W. Dunfee (1999). Ties That Bind: A Social Contracts Approach to Business Ethics. Boston, Harvard Business School.

Dwyer, S. (2008). Thinking Ethically in Business. Penrith, Humanities-Ebooks, LLP

Eakin, J. M., E. MacEachen, E. Mansfield and J. Clarke (2009). The Logic of Practice: An Ethnographic Study of Front-line Service Work with Small Businesses in Ontario's Workplace Safety and Insurance Board. Toronto, Institute for Work \& Health.

Esping-Andersen, G. (1990). The Three Worlds of Welfare Capitalism. Cambridge, Polity Press.

Fooks, G., A. Gilmore, J. Collin, C. Holden and K. Lee (2013). "The Limits of Corporate Social Responsibility: Techniques of Neutralization, Stakeholder Management and Political CSR." Journal of Business Ethics 112(2): 283-299. 
Franche, R.-L., R. Baril, W. Shaw, M. Nicholas and P. Loisel (2005a). "Workplace-Based Return-to-Work Interventions: Optimizing the Role of Stakeholders in Implementation and Research." Journal of Occupational Rehabilitation 15(4): 525-542.

Franche, R.-L., K. Cullen, J. Clarke, E. Irvin, S. Sinclair, J. Frank, et al. D. Van Eerd (2005b). "Workplace-Based Return-to-Work Interventions: A Systematic Review of the Quantitative Literature." Journal of Occupational Rehabilitation 15(4): 607-631.

Franche, R.-L., C. N. Severin, H. Lee, S. Hogg-Johnson, C. G. Hepburn, M. Vidmar and E. MacEachen (2009). "Perceived Justice of Compensation Process for Return-to-Work: Development and Validation of a Scale." Psychological Injury and Law 2(3): 225-237.

Garriga, E. and D. Melé (2004). "Corporate Social Responsibility Theories: Mapping the Territory." Journal of Business Ethics 53(1): 51-71.

Goodman, K. W. (2002). Ethics and Evidence-Based Medicine : Fallibility and Responsibility in Clinical Science. West Nyack, Cambridge University Press.

Gravel, S., B. Vissandjée, K. Lippel, J.-M. Brodeur, L. Patry and F. Champagne (2010). "Ethics and the Compensation of Immigrant Workers for Work-Related Injuries and Illnesses." Journal of Immigrant Minority Health 12(5): 707-714.

Harris, D. M. (2011). Ethics in Health Services and Policy: A Global Approach. San Fransisco, Jossey-Bass.

Hart, S. M. (2010). "Self-regulation, Corporate Social Responsibility, and the Business Case: Do they Work in Acheiving Workplace Equality and Safety?" Journal of Business Ethics 92(4): 585600 .

Hepburn, C. G., R.-L. Franche and L. Francis (2010a). "Successful return to work: the role of fairness and workplace-based strategies." International Journal of Workplace Health Management 3(1): 7-24.

Hepburn, C. G., E. K. Kelloway and R.-L. Franche (2010b). "Early Employer Response to Workplace Injury: What Injured Workers Perceive as Fair and Why These Perceptions Matter." Journal of Occupational Health Psychology 15(4): 409-420. 
Herrisone-Kelly, P. (2011). "Determining the common morality's norms in the sixth edition of Principles of Biomedical Ethics." Journal of Medical Ethics 37(10): 584-587.

Khushf, G., Ed. (2004). Handbook of Bioethics: Taking Stock of the Field from a Philosophical Perspective. Hingham, Kluwer Academic Publishers.

Korpi, W. and J. Palme (1998). "The paradox of redistribution and strategies of equality: Welfare state institutions, inequality, and poverty in the Western countries." American Sociological Review 63(5): 661-687.

Lawrence, D. J. (2007). "The Four Principles of Biomedical Ethics: A Foundation for Current Bioethical Debate." Journal of Chiropractic Humanities 14: 34-40.

Leinonen, T., O. Pietiläinen, M. Laaksonen, O. Rahkonen, E. Lahelma and P. Martikainen (2011). "Occupational social class and disability retirement among municipal employees - the contribution of health behaviors and working conditions." Scandinavian Journal of Work and Environmental Medicine 37(6): 464-472.

Lindqvist, R. (2003). "Vocational rehabilitation between work and welfare - the Swedish experience " Scandinavian Journal of Disability Research 5(1): 68-92.

Lippel, K. (1999). "Therapeutic and anti-therapeutic consequences of workers' compensation." International Journal of Law and Psychiatry 22(5-6): 521-546.

Lippel, K. (2003). "Compensation for musculoskeletal disorders in Quebec: Systemic discrimination against women workers?" International Journal of Health Services 33(2): 253-281.

Lippel, K. (2007). "Workers describe the effect of the workers' compensation process on their health: A Québec study." International Journal of Law and Psychiatry 30(4-5): 427-443.

Lippel, K. (2012). "Preserving Workers' Dignity in Workers' Compensation Systems: An International Perspective." American Journal of Industrial Medicine 55(6): 519-536.

Loisel, P. (2009). "Developing a new paradigm: Work disability prevention." ICOH Special issue.

Loisel, P., R. Buchbinder, R. Hazard, R. Keller, I. Scheel, M. van Tulder and B. Webster (2005). "Prevention of Work Disability Due to Musculoskeletal Disorders: The Challenge of Implementing Evidence." Journal of Occupational Rehabilitation 15(4): 507-524. 
Luhmann, N. (1995). Social Systems. Stanford, Stanford University Press.

Lundquist, L. (2007). Public Administration Theory and Public Administration Change. Public administration in transition: theory, practice, methodology. G. Gjelstrup and E. Sørensen. Copenhagen, DJØF.

MacEachen, E., S. Ferrier, A. Kosny and L. Chamber (2007). "A deliberation on 'hurt versus harm' logic in early-return-to-work policy." Policy and practice in health and safety 2: 41-62.

MacEachen, E., A. Kosny, S. Ferrier and L. Chamber (2010). "The "Toxic Dose" of System Problems: Why Some Injured Workers Don't Return to Work as Expected." Journal of Occupational Rehabilitation 20(3): 349-366.

MacEachen, E., A. Kosny, S. Ferrier, K. Lippel, C. Neilson, R.-L. Franche and D. Pugliese (2012). "The 'Ability' Paradigm in Vocational Rehabilitation: Challenges in an Ontario Injured Worker Retraining Program." Journal of Occupational Rehabilitation 22(1): 105-117.

Maignan, I. and O. C. Ferrell (2004). "Corporate Social Responsibility and Marketing: An Integrative Framework." Journal of the Academy of Marketing Science 32(1): 3-19.

Martinez, J. M. (2009). Public Administration Ethics for the 21st Century. Santa Barbara, ABCClio.

Murray, G. (2010). "Framing globalization and work: A research agenda." Journal of Industrial Relations 52(1): 11-25.

Müssener, U., M. Upmark, K. Festin and K. Alexanderson (2008). "Positive experiences of encounters with healthcare and social insurance professionals among people on long-term sick leave." Journal of Rehabilitation Medicine 40: 805-811.

Radnor, Z. J., M. Holweg and J. Waring (2012). "Lean in healthcare: The unfilled promise?" Social Science and Medicine 74(3): 364-371.

Rawls, J. (1971). A Theory of Justice. Cambridge, Harvard University Press.

Reilly, N. P., M. J. Sirgy and C. A. Gorman, Eds. (2012). Work and Quality of Life: Ethical Practices in Organizations. Radford, Springer. 
Rendtorff, J. D. (2009). Responsibility, Ethics and Legitimacy of Corporations. Frederiksberg, Copenhagen Business School Press

Roberts-Yates, C. (2003). "The concerns and issues of injured workers in relation to claims/injury management and rehabilitation: the need for new operational frameworks." Disability and Rehabilitation 25(16): 898-907.

Roberts, K. and W. Young (1997). "Procedural Fairness, Return to Work, and the Decision to Dispute in Workers' Compensation." Employee Responsibilities and Rights Journal 10(3).

Schwartz, M. S. and A. B. Carroll (2003). "Corporate Social Responsibility: A Three-Domain Approach." Business Ethics Quarterly 13(4): 503-530.

Seing, I., C. Ståhl, L. Nordenfelt, P. Bülow and K. Ekberg (2012). "Policy and Practice of Work Ability: A Negotiation of Responsibility in Organizing Return to Work." Journal of Occupational Rehabilitation 22(4): 553-564.

Stensöta, H. O. (2010). "The Conditions of Care: Reframing the Debate about Public Sector Ethics." Public Administration Review 70(2): 295-303.

Strunin, L. and L. I. Boden (2000). "Paths of Reentry: Employment Experiences of Injured Workers." American Journal of Industrial Medicine 38(4): 373-384.

Strunin, L. and L. I. Boden (2004). "The Workers' Compensation System: Worker Friend of Foe?" American Journal of Industrial Medicine 45(4): 338-345.

Ståhl, C., U. Müssener and T. Svensson (2012). "Implementation of standardized time limits in sickness insurance and return-to-work: Experiences of four actors." Disability and Rehabilitation 34(16): 1404-1411.

Svensson, T. and A. Björklund (2010). "Focus on health, motivation, and pride: A discussion of three theoretical perspectives on the rehabilitation of sick-listed people." Work 36: 273-282.

Tjulin, Å., E. MacEachen and K. Ekberg (2010). "Exploring Workplace Actors Experiences of the Social Organization of Return-to-Work." Journal of Occupational Rehabilitation 20(3): 311321. 
Treviño, L. K., G. R. Weaver and S. J. Reynolds (2006). "Behavioral ethics in organizations: A review." Journal of Management 32(6): 951-990.

Vaughn, B. T. (1998). "Ethical dilemmas encountered by private sector rehabilitation practitioners." Journal of Rehabilitation 64(4): 47-51.

Weaver, G. R., L. K. Treviño and P. L. Cochran (1999). "Corporate ethics practices in the mid1990's: An empirical study of the fortune 1000." Journal of Business Ethics 18(3): 283-294.

Westerholm, P. (2007). "Professional Ethics in Occupational Health - Western European Perspectives." Industrial Health 45(1): 19-25.

Westerholm, P., T. Nilstun and J. Øvretveit, Eds. (2004). Practical Ethics in Occupational Health. Oxford, Radcliffe Medical Press.

Vonk, G. J. and A. Tollenaar, Eds. (2010). Social security as a public interest : a multidisciplinary inquiry into the foundations of the regulatory welfare state. Antwerp, Intersentia.

Young, A. E., R. Wasiak, R. T. Roessler, K. M. McPherson, J. R. Anema and M. N. M. van Poppel (2005). "Return-to-Work Outcomes Following Work Disability: Stakeholder Motivations, Interests and Concerns." Journal of Occupational Rehabilitation 15(4): 543-556. 
Table 1: Ethical concepts applied to individual, organizational and societal level

\begin{tabular}{|l|l|l|l|}
\hline & Medicine & Business & Public administration \\
\hline Individual level & $\begin{array}{l}\text { Autonomy } \\
\text { Beneficence } \\
\text { Nonmalevolence } \\
\text { Justice }\end{array}$ & $\begin{array}{l}\text { Distributional justice } \\
\text { Interactional justice } \\
\text { Procedural justice } \\
\text { Nonmalevolence } \\
\text { Moral duties }\end{array}$ & $\begin{array}{l}\text { Citizenship/dignity } \\
\text { Beneficence } \\
\text { Nonmalevolence } \\
\text { Rights and obligations }\end{array}$ \\
\hline Organizational level & $\begin{array}{l}\text { Virtue } \\
\text { Professional ethics } \\
\text { Prioritizing resources }\end{array}$ & $\begin{array}{l}\text { Economy/profitability } \\
\text { Codes of ethics } \\
\text { Workplace safety }\end{array}$ & $\begin{array}{l}\text { Virtue/democratic ethos } \\
\text { Distributing resources }\end{array}$ \\
\hline Societal level & Social equity & $\begin{array}{l}\text { Law } \\
\text { Corporate identity } \\
\text { Stakeholder theories } \\
\text { Social contracts } \\
\text { Philanthropy }\end{array}$ & $\begin{array}{l}\text { Justice/social equity } \\
\text { Constitutional values } \\
\text { Public interest }\end{array}$ \\
& & & \\
\hline
\end{tabular}

